lisation, abortion and the moral status of the fetus and fetal experimentation. The author also discusses the more recent dilemmas of the new reproductive technologies, for instance the management of infertility and surrogacy. To assess Mason's ability to communicate the complexities of medical ethics one has only to turn to chapters five and ten on abortion and surrogacy. Abortion is often assumed to be a dead issue by the uninformed, but is and will remain very much a live and sensitive subject. Most writers who attempt to come to grips with abortion, the moral value of the embryo and fetus and surrogacy often reveal paradox or inconsistency in their thinking.

Mason makes the point that abortion is more than contraception. The former, he argues, seeks to prevent a life which is developing and the latter merely to prevent a life from beginning: he concludes that as the state has an interest in protecting human life, there exists a valid reason for statutory regulation of abortion. Mason argues that the critical point is to decide what form of human life is at stake and what level of protection it should be afforded. $\mathrm{He}$ then reports upon the opposing pro-life and pro-choice arguments on which the abortion debate is founded and identifies as significant the questions: when does human life begin and what is human life. Mason presents a balanced discussion and identifies his preferred stance as the gradualist approach at his conclusion. In this approach he persists throughout chapters six and seven, which are concerned with protection of the fetus and fetal experimentation.

Mason's attempt to grapple with the ethics of surrogacy is disappointing. Under the heading "moral aspects" he writes "Given that [the Human Fertilisation and Embryology Act 1990] provides satisfactory regulation of surrogacy, there seems little to choose between [adoption and contract pregnancies] from the child's point of view, insofar as the child [in the case of partial surrogacy] is returning to its biological father, the surrogacy arrangement is preferable...". In fact, the 1990 act is quite prohibitive of surrogacy arrangements: parenting orders only apply to commissioning couples who are married and when the surrogacy arrangement has worked out. This raises a whole host of questions about the moral values of the Legislature. Also, Mason's emphasis upon consanguinity is a very narrow viewpoint. Surely the intention of prospec- tive parents, whether adopting or commissioning, is more relevant. That is not to say that a focus upon intention alone is not problematic.

On the whole I found this text engaging and accessible. However, it cannot be described as an ethics text but is of value to moral philosophers who would like to consolidate their understanding with a knowledge of the realities of life, apparent in the frustrations of clinical practice and the legal process, and the law's preference for pragmatism. I was often frustrated that Mason preferred endnotes rather than footnotes. This is of more relevance not only to the lawyer, because the year in which the relevant cases were heard or reported is helpful information and is best placed as a footnote, but also to any reader who wishes to benefit from a chronological understanding of change.

ALISON BURTON

$M A$ in Medical Law and Ethics (Lond) MBBS (QLD) BMedSCi (TAS).

\section{Treating Eating Disorders: Ethical, Legal and Personal Issues}
Edited by Walter Vandereycken and Pierre J V Beaumont, London, The Athlone Press, 1998, 286 pages, $£ 45$ (hb) $£ 16.95(\mathrm{pb})$.

This is a thought-provoking book which considers the ethical, legal and personal issues involved in the treatment of eating disorders. The book tackles these issues from three different angles: firstly, the clinician's responsibility to act ethically and competently, secondly, the patient's competency with respect to compulsory treatment, and finally, the role of society in providing the right context for ethical management of eating disorders. The contributors are specialists in eating disorders with considerable experience in these areas. Excellent references are provided at the end of each chapter.

Chapter one highlights the paradoxes in treating eating disorders and the range of feelings experienced by the therapist. The dual and often conflicting responsibilities to treat the patient's illness effectively and to respect the patient's autonomy, wishes and values are well portrayed. In chapter two the authors suggest that therapists have an ethical responsibil- ity to understand both patients' a赵 their own personal feelings. Th chapters deal with the issue of gentr and its influence on therapy. This issege is brought to life by a personal accout of the experience of being a male therapist treating women with eatig disorders. The ethical issue of how engage patients while maintainiffy good professional boundaries is d cussed, highlighting the importance $9 f$ supervision. The writer emphasifes the need for therapists to understa $\overrightarrow{a r}$ the influence of their own family of origin as well as their attitudes to mate and female roles and relationships.

Three chapters deal with the contentious issue of compulsory treat ment. Chapter six provides a balanced account of the dilemmas in choosinga path between a paternalistic or utuintarian approach and a more libertarigh approach. The ethical principles of beneficence, non-maleficence, justice and utility are well argued in respect and the view is put forw that in certain cases compulsory tre $\mathrm{g}-$ ment is not a threat but a right. The्ष्ठ is a consideration of how compulsory treatment should be implemented, pointing out the inconsistencis legislation between and within tries. The need for more stafiad ethical guidelines and procedures noted. The following chapter d cusses more generally the legality of forced feeding in a range of situatio including hunger-strikes in priser. The issue of competence to consen touched on but I would like to haye seen more discussion regarding difficulties in assessing competence in people with eating disorders. There some mention of consent to treatmeht in minors, highlighting the anomales in the law. However, considering thrat many patients with eating disorders are under the age of 18 , the dilemmans raised by the treatment of minors ape perhaps not explored enough.

In chapter eight the writer arguess against compulsory treatment for an rexia nervosa. He emphasises importance of understanding the needs and wishes of patients, station that treatment contrary to patients, wishes may not satisfy the principle of beneficence and is almost always unethical. Limited knowledge of outcome of compulsory treatmentosis cited as another reason for being verry cautious about this approach. The writer also emphasises the possigfe change in consent over time and need to disentangle coercion frem compulsion. Alternatives to computsory treatment such as engaging the 
family are discussed, although this would surely be done anyway before embarking on compulsory treatment.

Ethical issues surrounding behavioural treatment are discussed, emphasising the relative lack of research on treatment outcome in anorexia nervosa. The authors are critical of the standard behavioural programmes that used to be popular in treating eating disorders. They advocate the use of a brief reward programme to enable weight gain from a life-threatening low weight, although as yet no research is available to support the use of this model.

Finally, the chapters on health care set the dilemmas in context by highlighting the difficulties in providing treatment for eating disorders within a context of rationing. Ethics and market forces are discussed well, particularly in relation to the treatment of eating disorders within the context of managed care in the US.

In summary, this is a readable and well-considered book which I would recommend to those interested in the ethical issues arising from treatment of eating disorders. This is a highly relevant and controversial area and the book provides a useful contribution to the debate.

ANNE STEWART

Consultant Adolescent Psychiatrist Highfield Family and Adolescent Unit, Warneford Hospital, Oxford

\section{Healing Dramas and Clinical Plots. The Narrative Structure of Experience}

\author{
Cheryl Mattingly, Cambridge, \\ Cambridge University Press, 1998, \\ 191 pages, $£ 14.95$ (sc).
}

Cheryl Mattingly is an anthropologist who has studied the practice of occupational therapists in Boston, Chicago and Los Angeles over the decade beginning 1986. Previous reports of the studies, particularly those dealing with narrative reasoning, have been published in books and journals. This new book on healing dramas is a drawing together of themes from previous research, and brings to the reader the resulting theoretical insights which Mattingly has developed during the course of this major ethnographic study. The purpose of the book is to describe an "ethnography of occupational therapy" focusing on therapeutic narrative, with a parallel discourse on the relationship between "narrative, action, and experience". To achieve this Mattingly relates her material to key thinkers in anthropology and philosophy including Ricoeur, Geertz, Heidegger and Dilthey. Mattingly writes movingly about the experience of disability and long term illness, and how narrative is used by the therapist to understand the patient's previous life and to build on that understanding to create future life opportunities.

Three major themes run through the book:

i. The author's experience of carrying out the studies, in particular her relationship with the therapists and their patients.

ii. The way in which narrative analysis could be used to make sense of the therapeutic encounters.

iii. The potential for theory development from the narrative analysis.

The book is written using a narrative structure, with a major story being the researcher's experiences. In addition there are a series of sub-stories which include: finding a narrative; what narrative means; understanding and interpreting narrative, and the relationship of story to self.

While the book is not written particularly with ethicists in mind, the whole focus of the content is about behaving well in the clinical setting. Mattingly writes that when considering morality in this setting the whole process "carries a moral resonance". This is translated in practical terms into the negotiation of the moral when working towards quality of life with people who have permanent disabilities. The potential for negotiation between health workers and their patients is seen to be more risky in fast track medical care where communication failures are most likely, when compared to slow track therapy where both more formal and informal time can be spent with the patient.

As an occupational therapist I was charmed and stimulated by the insights which the book sheds on day-to-day practice. Mattingly reminded me that not everyone is comfortable when communicating with people who have severe physical, intellectual or psychological illness, and refers to complex impairments as "biomedical disaster areas". She describes her need on occasion to leave the treatment room when faced with severe suffering, and admired the occupational therapists who routinely showed care and compassion. Mattingly also explores her lack of valuing of women's roles before undertaking this research, during which she had to review the world of women and domestic activity. She was eventually able to accept that housework and homemaking are central cultural concerns in patients' lives.

While much of the book describes the familiar face of occupational therapy, I was disconcerted by the concentration on the "clinical setting", and the use of language which included the words "patient", "illness", and "diagnosis". Many occupational therapists work in social and community settings where the medical model and application would not be seen as relevant to their practice. Mattingly's exploration of narrative in therapeutic encounters, and theoretical explanation of events is masterly. She starts her argument with the statement that "narratives are not just about experiences", but that narrative is created out of action, and fulfils a variety of other purposes. These include helping to shape the future, and exploring alternative ways of planning activities. Mattingly sees narrative as drama which is used in occupational therapy to lead to the "creation of desire". When working with people with disabilities failure was seen to arise when the patient did not "embrace the recuperative journey which involves adapting to one's new (disabled) body...".

At a time when virtue ethics are back on the ethical agenda, this book has a great deal to say about the virtuous occupational therapist and by association, other health care workers. Mattingly refers to the evangelical streak she saw in the therapists she observed, and to the moral issues which arose when the therapists penetrated the inner consciousness of their patients.

Occupational therapists worry that their skills are often seen as mundane and lacking the trappings of sophisticated technology or potential for major medical dramas. This book provides a celebration of ordinariness, "the ritual of the everyday", and uncovers the flexibility and complexity of therapy where the only tools the therapist has are herself and objects in her and her patient's immediate environment.

\section{ROSEMARY BARNITT}

School of Occupational Therapy and Physiotherapy, University of Southampton 